\title{
Prevalence of Human Immunodeficiency Virus Type 1 Drug Resistance Associated Mutations in Protease Cleavage and Non-Cleavage Sites and PTAP Motif Duplications in Indian HIV-1 Subtype C gag Regions
}

\author{
Sourav Sen ${ }^{1 *}$, Srikanth P. Tripathy ${ }^{2}$ and Ramesh S. Paranjape ${ }^{3}$ \\ ${ }^{1}$ Department of Microbiology, Armed Forces Medical College, Pune, Maharashtra, India \\ ${ }^{2}$ National Institute for Research in Tuberculosis (Indian Council of Medical Research), \\ Chennai, Tamil Nadu, India \\ ${ }^{3}$ National AIDS Research Institute (Indian Council of Medical Research), \\ Pune, Maharashtra, India \\ *Corresponding author
}

A B S T R A C T

HIV-1 protease is responsible for total twelve proteolytic reactions that are required to generate a viable virus. Mutations in gag cleavage and non-cleavage sites have been reported to aid in recovery of diminished replication capacity due to HIV resistance

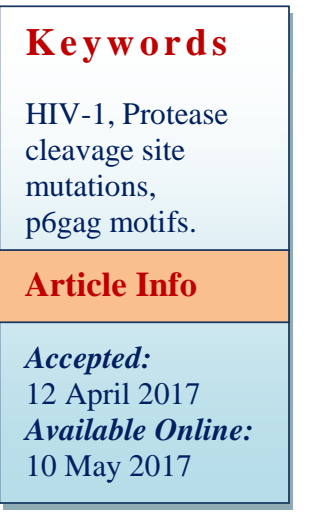
mutations in protease. Duplication of HIV-1 p6 gag proline-rich (PTAP) region, though not exclusively related to drug resistance, may improve the replication of HIV-1. In subtype C, PTAP/PSAP duplications have been reported to be significantly higher than that seen in non-C subtype sequences. We analyzed Indian HIV-1 gag gene amino acid sequences from antiretroviral drug treatment-naïve and treatment-experienced study participant specimens, which included 72 proviral (subtype $\mathrm{C}=70$; subtype $\mathrm{A} 1=2$ ) and 56 plasma (subtype $C=55$; subtype $A 1=1$ ) sequences. Sequences from one treatment-naïve and two PI-exposed study participants exhibited A431V mutation in gag, a mutation associated with PI resistance. The remaining sequences harboring such PI resistance associated mutations in gag were in those who were either treatment-naïve, or had been exposed to NRTIs and NNRTIs only. In the study sequences, the frequency of PTAP/PSAP duplications ranged from $16 \%$ in plasma to $20 \%$ in proviral DNA, with no statistically significant differences in the prevalence of these duplications between sequences from treatment-naïve and treatment-experienced individuals. There is a need to explore the phenotypic behavior and clinical correlates of mutations and duplications in non-B subtypes in protease cleavage and non-cleavage sites in gag, with relevance to HIV drug resistance.

\section{Introduction}

The HIV-1 protease is responsible for the cleavage of Gag, Gag-Pol and Nef precursor polyproteins. The process, occurring late in viral cycle, is highly specific, temporally regulated and essential for the production of infectious viral particles (Jacks et al., 1988;
Krausslich et al., 1989; Swanstrom et al., 1997). For the generation of a mature and viable virion, separate twelve proteolytic reactions are required, with individual reaction occurring at a specific cleavage site with unique amino acid arrangement (Billich 
et al., 1988). Each cleavage site is composed of the 5 amino acids upstream and the 5 amino acids downstream of the scissile bond. Protease cleaves the Gag precursor (p17/p24/p2/p7/p1/p6) in the order of (a) p2/p7, p17/p24, and p1/p6, (b) p7/p1, and (c) $\mathrm{p} 24 / \mathrm{p} 2$, with the cleavages of the $\mathrm{p} 7 / \mathrm{p} 1$ and p24/p2 being the steps that are slowest (Pettit et a.l, 2005). The main structural proteins are formed by cleavage of the Pr55 Gag polyprotein into matrix (MA; p17), capsid (CA; p24), nucleocapsid (NC; p7), p6 Gag, and two spacer peptides, $\mathrm{p} 2$ and $\mathrm{p} 1$.

\section{HIV-1 gag cleavage and non-cleavage site mutations and drug resistance}

Zhang et al reported for the first time the occurrence of mutations in the $g a g \mathrm{p} 7 / \mathrm{p} 1$ and p1/p6 cleavage sites along with sequential acquisition of protease resistance mutations at positions $46,82,54,71,89$, and 90 in patients receiving IDV therapy (Zhang et al., 1997). Changes at gag cleavage site positions 449 and 453 are selected, with associated decrease in susceptibility to APV, in presence of APV specific primary protease mutations (Maguire et al., 2002). Prado et al reported APVselected mutants with cross-resistance to LPV, and demonstrated that accumulation of two mutations in the protease (L10F/I84V), along with the gag L449F cleavage site mutation resulted in moderate levels of resistance to APV and LPV. Further, it was seen that a transition from double protease mutant $(\mathrm{L} 10 \mathrm{~F} / \mathrm{I} 84 \mathrm{~V})$ to the triple (L10F/M46I/I50V) or the quadruple (L10F/M46I/I47V/I50V) protease mutants increased LPV cross-resistance from 7.7- to a 19- and 31-fold change in IC50, respectively (Prado et al.,2002). After analysis of the relationship between 63 protease mutations and 21 gag CS mutations, two patterns of mutations in the protease have been identified. M46I/L, I54V, and V82A/T/F mutations in protease have been found to be associated with the A431V in gag, and $\mathrm{K} 20 \mathrm{I} / \mathrm{R} / \mathrm{M}$, L89M/I mutations in protease with S373Q and L449P in gag (Malet et al., 2007).

On comparison of the specificities of the mutant proteases to that of wild-type HIV using combinatorial libraries of peptide substrates, it has been demonstrated that at times the accumulation of mutations in the protease results in subtle changes in substrate specificity. These changes are accompanied by substitutions in the $\mathrm{NC} / \mathrm{p} 1$ cleavage site of the corresponding virus. These mutations may represent a mechanism by which severely compromised, drug-resistant viral strains can increase fitness levels (Dauber et al., 2002). Nijhuis et al., have shown that increased polyprotein processing due to mutations in the natural substrate rather than the enzyme itself represents a novel mechanism by which HIV1 develops resistance to PIs. While the PIresistant viruses did not have a single substitution in the viral protease, full genomic sequencing revealed the presence of $\mathrm{NC} / \mathrm{p} 1$ cleavage site substitutions in the viral gag (K436E and/or I437T/V) in all three resistant viruses. These changes, when introduced in a reference strain, conferred PI resistance, this being attributed to the enhancement of processing efficiency of altered substrate by wild-type protease (Nijhuis et al., 2007)

Amino acid substitutions at non-cleavage sites in the Gag protein namely, L75R, H219Q, V390D/V390A, R409K, and E468K have been shown to exist in HIV-1 mutants selected against the PIs (Gatanaga et al., 2002). Following analyses of replication profiles, it has been demonstrated that these mutations are indispensable in presence of PIs, thereby suggesting that such mutations in gag non cleavage sites aid in recovery of diminished replication capacity due to HIV resistance mutations in protease (Gatanaga et al., 2002). 


\section{Role of PTAP motif in HIV-1 gag}

HIV-1 Gag late (L) domain is encoded by a peptide motif, Pro-Thr/Ser-Ala-Pro (PTAP) in the C-terminal, p6 domain of Pr55Gag. Mutations in the PTAP motif of p6 or deletion of the p6 domain result in inefficient budding and defective virus particle production (Gottlinger et al., 1991; Huang et al., 1995; Demirov et al., 2002). Fu et al have proposed that there is a link between the maturation of virion morphology and the viral RNA dimer. HIV-1 gag mutant that lacked a functional PTAP motif and produced immature virions without major defects in viral protein cleavage was studied. It was found that HIV-1 RNA dimer, extracted from cell-free virus particles, in the PTAP mutant is more fragile and unstable compared with those from $w t$ HIV-1 (Fu et al., 2006).

\section{Materials and Methods}

Study participants included antiretroviral drug treatment-naïve and treatment-experienced HIV-1 infected individuals enrolled between June 2004 and September 2006 at the National AIDS Research Institute (Indian Council of Medical Research), Pune, India. Written informed consent was taken from all the participants before sample collection. The PCR Amplification and sequencing analyses for generating the study sequences have been published by us previously (Sen et al., April 2007; Sen et al., October 2007]. Briefly, the pol gene region encoding protease (PR) and the 5'-end of reverse transcriptase (RT) was amplified by nested polymerase chain reaction (PCR) with outer primers, Pol 2021F (5'-AAGGCTGTTGGAAATGTGG-3') and Pol 4011R (5'-TGTTTACTTCTGATC CTGAATC-3'), and inner primer sets, either Pol 2032F (5'-AAATGTGGAAAGGA AGGACAC-3') and Pol 3999R (5'CCTGAATCTTGCAAAGCTAG-3') or Pol 2041F (5'-AAGGAAGGACACCAAAT GAAAG-3') and Pol 3768R (5'-
GCCAATAGTCTGTCCACCATG-3'). The PCR amplicons were sequenced bidirectionally using sequencing primers PolF 2493 (5'-CCTGTCAACATAATTGGAAG3'), PolF 3012 (5'-GGATCACCAGCAA TATTC- 3'), PolF 3403 (5'-GGGCCA AAGTACTAACAG-3'), PolR 2557 (5'GGTACAGTTTCAATGGGAC-3'), PolR 3117 (5'-CCCTATTTCTAAGTCAGATCC3'), and PolR 3620 (5'-TAGTGTGGGC AGTCCTC-3') along with the inner primers.

The HIV-1 gag gene amino acid sequences from specimens which were analyzed in this study included 72 proviral (subtype $\mathrm{C}=70$; subtype $\mathrm{A} 1=2$ ) and 56 plasma (subtype $\mathrm{C}=$ 55; subtype $\mathrm{A} 1=1$ ) sequences. The number of sequences that were analyzed for (a) mutations and substitutions in gag cleavage and non-cleavage site residues associated with antiretroviral resistance, and (b) PTAP/PSAP motif duplications in $\mathrm{p} 6$ region are shown in table 1. Chi square test was used for statistical analysis, and cut off $P$ value of $\leq 0.05$ was considered as significant.

\section{Results and Discussion}

\section{HIV-1 resistance associated gag cleavage} and non-cleavage site mutations

The mutations associated with antiretroviral drug resistance in HIV-1 gag that were analyzed included codons in NC/p1 cleavage site (codons 431, 436 and 437), p1/p6 cleavage site (codons 449 and 453), and p6 region (non-cleavage site; codon 468). The resistance associated mutations and substitutions observed in the study sequences are shown in table 3, along with ancestral subtype $\mathrm{A} 1$ and $\mathrm{C}$ sequences.

\section{Duplications in HIV-1 p6gag region motifs}

The number of duplications in PTAP/PSAP motif ranged from $16.33 \%$ in plasma sequences $(n=49)$ to $20 \%$ in proviral 
sequences $(n=70)$. However, there was no statistical difference in the frequency of this motif duplication between the sequences from treatment-naïve and treatment-experienced participants (Table 2).

HIV-1 drug resistance associated gag cleavage and non-cleavage site mutations

In our study, the codons in gag region, associated with HIV-1 resistance, that were available for analysis included 431, 436 and
437 in NC/p1 cleavage site, 449 and 453 in p1/p6 cleavage site, and 468 in p6 region (non-cleavage site). The ancestral subtype A1 and $\mathrm{C}$ residues at these positions were identical when compared to $\mathrm{HxB} 2$, except for an $\mathrm{L}$ to $\mathrm{P}$ substitution at residue 449 in ancestral subtype A1 (Table 3).

A431V, a gag mutation associated with resistance to PIs, was seen in sequences from one treatment-naïve and two treatmentexperienced study participants.

Table.1 The number of HIV-1 study participant sequences available for analysis of mutations and substitutions in gag cleavage and non-cleavage site residues associated with antiretroviral resistance and PTAP/PSAP motif duplications in p6 region

\begin{tabular}{|c|c|c|c|c|c|}
\hline \multirow{2}{*}{\multicolumn{2}{|c|}{ Study sequences }} & \multicolumn{3}{|c|}{$\begin{array}{l}\text { HIV-1 drug resistance associated } \\
\text { gag mutations and substitutions }\end{array}$} & \multirow{2}{*}{$\begin{array}{c}\text { PTAP/PSAP motif } \\
\text { duplications in HIV-1 } \\
\text { p6 region }\end{array}$} \\
\hline & & NC/p1 & p1/p6gag & p6 & \\
\hline \multirow[b]{2}{*}{ Proviral } & Treatment naive & 16 & 18 & 22 & 20 \\
\hline & $\begin{array}{l}\text { Treatment } \\
\text { experienced }\end{array}$ & 48 & 50 & 53 & 50 \\
\hline \multirow[t]{2}{*}{ Plasma } & Treatment naive & 17 & 20 & 20 & 20 \\
\hline & $\begin{array}{l}\text { Treatment } \\
\text { experienced }\end{array}$ & $24^{*}$ & 26 & 30 & 29 \\
\hline
\end{tabular}

*Of the 3 codons (A431, K436, I437) analyzed in NC/p1 region, there were 24 plasma sequences available for $\mathrm{K} 436$, and I437 and 23 plasma sequences for A431.

Table.2 PTAP/PSAP duplications in HIV-1 p6 gag region of study subtype C sequences

\begin{tabular}{|l|c|c|c|c|}
\hline & \multicolumn{2}{|c|}{ Proviral Sequences } & \multicolumn{2}{c|}{ Plasma Sequences } \\
\cline { 2 - 5 } & $\begin{array}{l}\text { Treatment- } \\
\text { naïve }\end{array}$ & $\begin{array}{l}\text { Treatment- } \\
\text { experienced }\end{array}$ & $\begin{array}{l}\text { Treatment- } \\
\text { naïve }\end{array}$ & $\begin{array}{l}\text { Treatment- } \\
\text { experienced }\end{array}$ \\
\hline $\begin{array}{l}\text { PTAP/PSAP } \\
\text { duplications }\end{array}$ & 1 & 13 & 2 & 6 \\
\hline P value & \multicolumn{2}{|c|}{$\mathrm{P}=0.09$} & \multicolumn{2}{c|}{$\mathrm{P}=0.5$} \\
\hline Frequency (\%) & \multicolumn{2}{|c|}{20} & \multicolumn{2}{c|}{16.33} \\
\hline
\end{tabular}


Table.3 HIV-1 drug resistance associated gag cleavage and non-cleavage site mutations and substitutions in study sequences

\begin{tabular}{|c|c|c|c|c|c|c|c|}
\hline \multicolumn{2}{|c|}{ HIV-1 gag codon ${ }^{a}$} & A431 & K436 & I437 & L449 & $\mathbf{P 4 5 3}$ & E468 \\
\hline \multirow{3}{*}{$\begin{array}{l}\text { Proviral } \\
\text { sequences }^{b}\end{array}$} & Treatment-naïve [C] & $\mathbf{V}^{1}$ & --- & $\begin{array}{ll}-- \\
\end{array}$ & --- & $\mathrm{T}^{1}$ & --- \\
\hline & Treatment-experienced [C] & $\mathbf{V}^{1}$ & $\mathrm{R}^{3}$ & $\mathrm{~L}^{1}$ & $\mathrm{H}^{\mathrm{I}} \mathrm{Q}^{\mathrm{I}}$ & $\mathbf{L}^{2} \mathrm{I}^{1}$ & $\mathrm{G}^{1} \mathrm{~K}^{1} \mathrm{Q}^{2}$ \\
\hline & $\begin{array}{l}\text { Treatment-experienced } \\
\text { [A1] }\end{array}$ & --- & $\mathrm{R}^{2}$ & --- & $\mathbf{P}^{2}$ & $\mathbf{L}^{2}$ & --- \\
\hline \multirow{3}{*}{$\begin{array}{l}\text { Plasma } \\
\text { sequences }^{\text {b }}\end{array}$} & Treatment-naïve [C] & --- & --- & --- & $\mathrm{I}^{1}$ & $\mathbf{L}^{1}$ & $\mathrm{G}^{4}$ \\
\hline & Treatment-experienced [C] & $\mathbf{V}^{1}$ & $\mathrm{R}^{1}$ & $\mathrm{~L}^{2} \mathbf{V}^{1}$ & $\mathbf{P}^{1}$ & $\mathbf{L}^{1} \mathrm{I}^{1}$ & $A^{1}$ \\
\hline & $\begin{array}{l}\text { Treatment-experienced } \\
\text { [A1] }\end{array}$ & --- & $\mathrm{R}^{1}$ & --- & $\mathbf{P}^{1}$ & $\mathbf{L}^{1}$ & --- \\
\hline
\end{tabular}

a - The codons for HIV-1 gag are shown as single-letter amino acid codes succeeded by specific positions associated with drug resistance relative to the HXB2 sequence.

$\mathrm{b}$ - The specific resistance associated mutations (in bold letters) and substitutions are shown as single-letter amino acid codes followed by the number (in superscript) of HIV-1 study sequences with the mutation / substitution.

The proviral sequence (GenBank accession number DQ826611) from the treatment-naïve individual with the mutation A431V did have any associated protease resistance mutation. Of the two sequences from treatmentexperienced participants, one was proviral DNA (GenBank accession number EF186928), the other being plasma sequence (GenBank accession number EF186983). While the former had been exposed to NFV and RTV, and harbored protease resistance mutations (Major: M46L, V82A, and L90M; and Minor: L10V, A71V, and T74P), the latter had experienced IDV and RTV therapy, and exhibited major (M46L, I54V, V82A) as well as minor (L10I, L24I, A71V) protease resistance mutations. The association of protease mutations $(\mathrm{M} 46 \mathrm{I} / \mathrm{L}, \quad \mathrm{I} 54 \mathrm{~V}$ and $\mathrm{V} 82 \mathrm{~A} / \mathrm{T} / \mathrm{F}$ ) with A431V, following PI therapy, has been reported previously in HIV1 subtype B strains (Malet et al., 2007). In individuals on Darunavir containing PI regimen experiencing treatment failure, an association between the presence of A431V in gag and selection of L76V mutation in the protease has been reported (Lambert-Niclot et al., 2008), and a similar association of L76V strictly occuring either together with M46I and/or A431V in patients failing protease inhibitor therapies has been seen (Knops et al., 2010). The effect of Gag on resistance has been shown to depend on the presence of cleavage site mutations A431V or I437V in NC-SP2-p6 and correlates with processing of the NC/SP2 cleavage site. Mutations in the NC-SP2-p6 region of Gag appear to be critical for viral fitness and development of resistance both in presence and absence of PIs (Dam et al., 2009). Further, recently, presence of A431V has been demonstrated to abrogate cytotoxic $\mathrm{T}$ cell (CTL) recognition, thus suggesting a possible influence of development of this drug resistance mutation on the CTL response (Verheyen et al., 2010).

HIV-1 gag mutation P453L, which is associated with protease resistance mutations following APV therapy (Maguire et al., 2002), was observed in one proviral (GenBank accession number EF186929) and one plasma (GenBank accession number EF186978) study sequence each, both being from the same study participant who had experienced IDV and RTV treatment. The protease major mutations - M46I, I54L and L90M; and protease minor mutations - L10Y, L24F, A71V, and G73ST were present in both the sequences. L23I was an additional protease minor mutation observed in the proviral sequence. Apart from these study 
participant sequences, $\quad \mathrm{P} 453 \mathrm{~L} / \mathrm{I} / \mathrm{T}$ mutation/substitution were observed in certain treatment-naïve as well as treatmentexperienced (but unexposed to PIs) study participants (Table 3). In this context, it has been reported that natural polymorphism 453T, which are common in HIV non-B subtypes, appear to favour the selection of CS mutation 453I rather than treatment-associated CS mutation 453L (Knops et al., 2010).

The remaining HIV-1 resistance associated gag cleavage site (I437V and L449P) and non-cleavage site (E468A) mutations were observed in sequences from treatmentexperienced study participants only, who, however, had not been exposed to PIs (Table 3). Of these, I437V/T in gag can lead to resistance against Darunavir wherein no additional resistance mutations need to be selected (Lambert-Niclot et al., 2008).

Thus, there were three PI-exposed study HIV1 subtype $\mathrm{C}$ sequences harboring already reported known gag mutations, namely $\mathrm{A} 431 \mathrm{~V}$ and $\mathrm{P} 453 \mathrm{~L}$, associated with protease mutations. The phenotypic behavior associated with the gag mutations and substitutions observed in remaining subtype $\mathrm{A} 1$ and $\mathrm{C}$ sequences from treatment-naïve as well as treatment-experienced (but unexposed to PIs) individuals is yet to be elucidated.

\section{PTAP/PSAP motif duplication and HIV-1 drug resistance}

Tamiya et al., demonstrated for the first time that the inserts seen in the proximity of the gag cleavage sites in highly multi-PI resistant HIV-1 variants restore the otherwise compromised enzymatic activity of mutant protease, enabling the multi-PI-resistant HIV1 variants to remain replication competent. Unique insertions (TGNS, SQVN, AQQA, SRPE, APP, and/or PTAPPA) near the p17/p24 and p1/p6 gag cleavage sites were identified, in addition to the known resistance-related multiple amino acid substitutions within the protease in full-length molecular infectious multidrug-resistant HIV1 clones generated from HIV-1 variants isolated from failing patients. This data showed that amino acid insertions in the proximity of gag cleavage sites improve the otherwise compromised replication of HIV-1 variants that are highly resistant to multiple PIs (Tamiya et al., 2004).

Flys et al analyzed sequence variations in the HIV-1 gag p6 region using plasma samples from 22 individuals with non-subtype B HIV1 infection [subtypes A, C, D, F, and G, and circulating recombinant forms (CRFs) CRF01-AE and CRF02_AG], and found that while PTAP duplications were commoner in subtype $\mathrm{C}, \mathrm{KQE}$ duplications were present in subtype B only (Flys et al., 2005).

Gallego et al reported duplication of the PTAP motif appeared at similar rates among drug-naive and pretreated individuals. In comparison, duplications of the KQE motif of the p6Gag protein were observed in samples from antiretroviral therapy-experienced subjects only (Gallego et al., 2003). Brumme et al also reported that insertions within the HIV-1 p6Gag proline-rich (PTAP) region are not exclusively related to drug resistance and may not influence response to antiretroviral therapy (Brumme et al., 2003). After studying 117 subtype $\mathrm{C}$ sequences, Flys et al., found that $27 \%$ sequences harbored PTAP/PSAP duplications, which was significantly higher than that seen in non-C subtype sequences (9.2\%). Following estimation of HIV-1 RNA levels and phenotype characterization of 12 subtype $\mathrm{C}$ isolates, of which 4 were with- and 8 without PTAP duplications, the differences in antiretroviral drug susceptibility or viral replication capacity were found to be not significant (Flys et al., 2005). 
In our study, the frequency of PTAP / PSAP duplications ranged from $16.3 \%$ in plasma sequences to $20 \%$ in proviral sequences, with no statistical difference in the distribution of this duplication in sequences from treatmentnaïve and treatment-experienced study participants. KQE motif duplication was not observed in any of our study sequences. Recently, sequence duplication of the PTAP motif has been reported amongst subtype $C$ viral isolates from HIV-1 seropositive drugnaive study participants from India and Africa (Sharma et al., 2017).

While exploring the relevance of cleavage site mutations in non-B subtypes, consideration has be given to mutations that are naturally occurring polymorphisms as well, which have been otherwise been identified as gag mutations associated with PI resistance (based on subtype B phenotypic behavior). Also, whether substitutions at such polymorphic residues in non-B subtypes lead to an inherently altered phenotypic response in presence of ARV drugs needs to be explored. The role of PTAP/PSAP duplication, a motif essential for virus budding and maturation, in subtype C, the predominant HIV-1 subtype, in relation to response to ARV therapy and HIV disease needs to be investigated in detail since the current data about the same is limited.

The sequences of the study isolates are available under GenBank accession numbers mentioned below:

\section{Proviral naive sequences}

$\begin{array}{lll}\text { ABI32037, } & \text { ABI32039, } & \text { ABI32041, } \\ \text { ABI32043, } & \text { ABI32045, } & \text { ABI32047, } \\ \text { ABI32049, } & \text { ABI32051, } & \text { ABI32053, } \\ \text { ABI32055, } & \text { ABI32057, } & \text { ABI32059, } \\ \text { ABI32061, } & \text { ABI32063, } & \text { ABI32065, } \\ \text { ABI32067, } & \text { ABI32069, } & \text { ABI32071, } \\ \text { ABI32073, } & \text { ABI32075, } & \text { ABI32077, } \\ \text { ABI32079, ABI32081, ABI32083, ABI32085 }\end{array}$

Proviral treatment-experienced sequences

$\begin{array}{lcc}\text { ABI32087, } & \text { ABI32090, } & \text { ABI32092, } \\ \text { ABI32094, } & \text { ABI32096, } & \text { ABI32098, } \\ \text { ABI32100, } & \text { ABI32102-32103, } & \text { ABI32105, } \\ \text { ABI32107, } & \text { ABI32109, } & \text { ABI32111, } \\ \text { ABI32113, } & \text { ABI32115, } & \text { ABI32117, } \\ \text { ABI32119, } & \text { ABI32121, } & \text { ABI32123, } \\ \text { ABI32125, } & \text { ABI32127, } & \text { ABI32129, } \\ \text { ABI32130, } & \text { ABI32131, } & \text { ABI32133, } \\ \text { ABI32135, } & \text { ABI32137, } & \text { ABI32139, } \\ \text { ABI32141, } & \text { ABI32143, } & \text { ABI32145, } \\ \text { ABI32147, } & \text { ABI32149, } & \text { ABI32151, } \\ \text { ABI32153, } & \text { ABI32155, } & \text { ABI32157, } \\ \text { ABI32159, } & \text { ABI32161, } & \text { ABI32163, } \\ \text { ABI32165, } & \text { ABI32167, } & \text { ABI32169, } \\ \text { ABI32171, } & \text { ABI32173, } & \text { ABI32175, } \\ \text { ABI32177, } & \text { ABI32179, } & \text { ABI32181, } \\ \text { ABI32183, ABL85621, EF186926-186929, } \\ \text { EF186931-186932 }\end{array}$

Plasma naive sequences

EF186933 - EF186954

Plasma treatment-experienced sequences

EF186955 - EF186988

\section{References}

Billich, S., Knoop, M.T., Hansen, J., et al., 1988. Synthetic peptides as substrates and inhibitors of human immune deficiency virus-1 protease. J. Biol. Chem., 263(34): 17905-17908.

Brumme, Z.L., Chan, K.J., Dong, W.W., et al., 2003. Prevalence and clinical implications of insertions in the HIV-1 p6Gag N-terminal region in drug-naive individuals initiating antiretroviral therapy. Antivir. Ther., 8(2): 91-96.

Dam, E., Quercia, R., Glass, B., et al., 2009. Gag Mutations Strongly Contribute to HIV-1 Resistance to Protease Inhibitors in Highly Drug-Experienced Patients besides Compensating for Fitness Loss. 
PLoS Pathog. 5(3): e1000345. doi:10.1371/journal.ppat.1000345.

Dauber, D.S., Ziermann, R., Parkin, N., et al., 2002. Altered substrate specificity of drug-resistant human immunodeficiency virus type 1 protease. J. Virol., 76(3): 1359-1368.

Demirov, D.G., Orenstein, J.M., Freed, E.O. 2002. The late domain of human immunodeficiency virus type $1 \mathrm{p} 6$ promotes virus release in a cell typedependent manner. J. Virol., 76(1): 105117.

Flys, T., Marlowe, N., Hackett, J., et al., 2005. Analysis of PTAP duplications in the gag p6 region of subtype C HIV type 1. AIDS Res. Hum. Retroviruses, 21(8):739-741.

Fu, W., Dang, Q., Nagashima, K., Freed, E.O., Pathak, V.K., Hu, W.S. 2006. Effects of Gag mutation and processing on retroviral dimeric RNA maturation. J. Virol., 80(3): 1242-1249.

Gallego, O., de Mendoza, C., Corral, A., Soriano, V. 2003. Changes in the human immunodeficiency virus p7-p1p6 gag gene in drug-naive and pretreated patients. J. Clin. Microbiol., 41(3): 1245-1247.

Gatanaga, H., Suzuki, Y., Tsang, H., et al., 2002. Amino acid substitutions in Gag protein at non-cleavage sites are indispensable for the development of a high multitude of HIV-1 resistance against protease inhibitors. J. Biol. Chem., 277(8): 5952-5961.

Gottlinger, H.G., Dorfman, T., Sodroski, J.G., Haseltine, W.A. 1991. Effect of mutations affecting the p6 gag protein on human immunodeficiency virus particle release. Proc. Natl. Acad. Sci. U $S$ A, 88(8): 3195-3199.

Huang, M., Orenstein, J.M., Martin, M.A., Freed, E.O. 1995. p6Gag is required for particle production from full-length human immunodeficiency virus type 1 molecular clones expressing protease. $J$. Virol., 69(11): 6810-6818.

Jacks, T., Power, M.D.,, Masiarz, F.R., Luciw, P.A., Barr, P.J., Varmus, H.E. 1988. Characterization of ribosomal frame shifting in HIV-1 gag-pol expression. Nature, 331(6153): 280283.

Knops, E., Däumer, M., Awerkiew, S., et al., 2010. Evolution of protease inhibitor resistance in the gag and pol genes of HIV subtype G isolates. J. Antimicrob. Chemother., 65(7): 1472-1476.

Knops, E., Kemper, I., Schülter, E., Pfister, H., Kaiser, R., Verheyen, J. 2010. The evolution of protease mutation $76 \mathrm{~V}$ is associated with protease mutation 46I and gag mutation 431V. AIDS, 24(5): 779-81.

Krausslich, H.G., Ingraham, R.H., Skoog, M.T., Wimmer, E., Pallai, P.V., Carter, C.A. 1989. Activity of purified biosynthetic proteinase of human immunodeficiency virus on natural substrates and synthetic peptides. Proc. Natl. Acad. Sci. U S A, 86(3): 807-811.

Lambert-Niclot, S., Flandre, P., Malet, I., et al., 2008. Impact of gag mutations on selection of darunavir resistance mutations in HIV-1 protease. $J$. Antimicrob. Chemother., 62: 905-908.

Maguire, M.F., Guinea, R.., Griffin, P., et al., 2002. Changes in human immunodeficiency virus type $1 \mathrm{Gag}$ at positions L449 and P453 are linked to I50V protease mutants in vivo and cause reduction of sensitivity to amprenavir and improved viral fitness in vitro. J. Virol., 76(15): 7398-7406.

Malet, I., Roquebert, B., Dalban, C., et al., 2007. Association of Gag cleavage sites to protease mutations and to virological response in HIV-1 treated patients. $J$. Infect., 54(4): 367-374.

Nijhuis, M., van Maarseveen, N.M., Lastere, S., et al., 2007. A Novel Substrate- 
Based HIV-1 Protease Inhibitor Drug Resistance Mechanism. PLoS Med., 4(1): e36.

Pettit, S.C., Clemente, J.C., Jeung, J.A., Dunn, B.M., Kaplan, A.H. 2005. Ordered processing of the human immunodeficiency virus type $1 \mathrm{GagPol}$ precursor is influenced by the context of the embedded viral protease. J. Virol., 79(16): 10601-10607.

Prado, J.G., Wrin, T., Beauchaine, J., et al., 2002. Amprenavir-resistant HIV-1 exhibits lopinavir cross-resistance and reduced replication capacity. AIDS, 16(7): 1009-1017.

Sen, S., Tripathy, S.P., Chimanpure, V.M., Patil, A.A., Bagul., R.D., Paranjape, R.S. 2007. Human immunodeficiency virus type 1 drug resistance mutations in peripheral blood mononuclear cell proviral DNA among antiretroviral treatment naïve and treatment experienced patients from Pune, India. AIDS Res Hum Retroviruses, 23(4): 489-97.

Sen, S., Tripathy, S.P., Patil, A.A., Chimanpure, V.M., Paranjape, R.S. 2007. High prevalence of human immunodeficiency virus type 1 drug resistance mutations in antiretroviral treatment experienced patients from Pune, India. AIDS Res Hum Retroviruses, 23(10): 1303-8.

Sharma, S., Aralaguppe, S. G., Abrahams, M.-R., Williamson, C., Gray, C., Balakrishnan, P., Saravanan, S.,
Murugavel, K.G., Solomon, S., Ranga, U. 2017. The PTAP sequence duplication in HIV-1 subtype C Gag p6 in drug-naive subjects of India and South Africa. BMC Infect. Dis., 17: 95.

Swanstrom, R., and Wills, J.W. 1997. Retroviral gene expression. II. Synthesis, processing, and assembly of viral proteins, p. 263-334. In J. M. Coffin, S. H. Hughes, and H. E. Varmus (ed.), Retroviruses, Cold Spring Harbor Laboratory, Cold Spring Harbor, N.Y.

Tamiya, S., Mardy, S., Kavlick, M.F., Yoshimura, K., Mistuya, H. 2004. Amino acid insertions near Gag cleavage sites restore the otherwise compromised replication of human immunodeficiency virus type 1 variants resistant to protease inhibitors. J. Virol., 78(21): 12030-12040.

Verheyen, J., Schweitzer, F., Harrer, E.G., Knops, E., Mueller, S.M., Däumer, M., Eismann, K., Bergmann, S., Spriewald, B.M., Kaiser, R., Harrer, T. 2010. Analysis of immune selection as a potential cause for the presence of cleavage site mutation $431 \mathrm{~V}$ in treatment-naive HIV type-1 isolates. Antivir. Ther., 15(6): 907-12.

Zhang, Y.M., Imamichi, H., Imamichi, T., et al., 1997 Drug resistance during indinavir therapy is caused by mutations in the protease gene and in its Gag substrate cleavage sites. J. Virol., 71(9): 6662-6670.

\section{How to cite this article:}

Sourav Sen, Srikanth P. Tripathy and Ramesh S. Paranjape. 2017. Prevalence of Human Immunodeficiency Virus Type 1 Drug Resistance Associated Mutations in Protease Cleavage and Non-Cleavage Sites and PTAP Motif Duplications in Indian HIV-1 Subtype C gag Regions. Int.J.Curr.Microbiol.App.Sci. 6(5): 1322-1330. doi: https://doi.org/10.20546/ijcmas.2017.605.143 